\title{
ANÁLISE GEOSSISTÊMICA DA BACIA HIDROGRÁFICA DO RIO ANINGAS - PIRAMBU, SERGIPE
}

Neise Mare de Souza Alves ${ }^{\text {(a) }}$, Débora Barbosa da Silva ${ }^{(b)}$, Izabella Santos de Macêdo Carvalho (c), Alisson Amorim de Menezes ${ }^{(\mathrm{d})}$

(a) Departamento de Geografia, Universidade Federal de Sergipe, neisemare@ gmail.com

(b) Departamento de Geografia, Universidade Federal de Sergipe, deborabarbs@ gmail.com

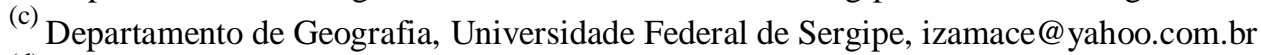

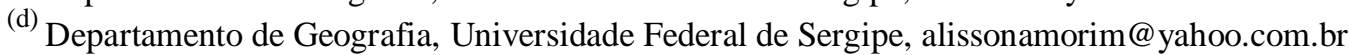

\section{EIXO: BACIAS HIDROGRÁFICAS E RECURSOS HÍDRICOS: ANÁLISE, PLANEJAMENTO E GESTÃO}

\begin{abstract}
Resumo
Este trabalho apresenta resultados dos estudos realizados na bacia do Rio Aningas, baseados modelo teórico-metodológico proposto por Bertrand (1972), objetivando analisar os geossistemas que compõem sua paisagem. Os procedimentos metodológicos foram: levantamento bibliográfico, análise do material cartográfico e trabalhos de campo. Foram identificados dois Geossistemas - Tabuleiros Costeiros e Planície Costeira, compostos respectivamente por quatro e três Geofácies. Cada Geofácie apresenta um determinado estágio evolutivo, consequente das alterações nos componentes do sistema natural e das intervenções antrópicas, no decorrer do tempo. Estas mudanças se refletem da dinâmica hidrográfica da bacia do rio Aningas e na atuação processos morfogenéticos. Foram identificadas três categorias de Geofácies em: resistasia natural e resistasia antrópica, onde predominam processos erosivos e, biostasia precária, cuja atuação ou não de processos erosivos depende diretamente do tipo de uso pelo fator antrópico. Esta análise pode subsidiar o planejamento ambiental e gerenciamento dos recursos hídricos no município de Pirambu.
\end{abstract}

Palavras chave: Análise geossistêmica; bacia do rio Aningas; recursos hídricos; paisagem.

\section{Introdução}

Os estudos desenvolvidos em bacias hidrográficas são crescentes, na atualidade. Este interesse reflete a preocupação das sociedades tanto em relação a conservação dos recursos hídricos quanto a qualidade da água. Nessa perspectiva, tais estudos têm contribuído para a manutenção, gestão e conservação dos sistemas hidrográficos, oferecendo informações relevantes que possibilitam a tomada de decisões por parte dos gestores públicos.

Para realizar esse tipo de análise no âmbito das bacias hidrográficas, torna-se necessário reconhecer a complexa relação entre a dinâmica da natureza e da sociedade, exigindo que o pesquisador busque entender como se estabelecem as interações entre os elementos que compõem o sistema ambiental dominante na paisagem em que se insere a bacia. 
XVII Simpósio Brasileiro

de Geografia Física Aplicada

I Congresso Nacional

de Geografia Física
OS DESAFIOS DA GEOGRAFIA FÍSICA NA FRONTEIRA DO CONHECIMENTO

Instituto de Geociências - Unicamp

Campinas - SP

28 de Junho à 02 de Julho de 2017

Desse modo, os princípios sistêmicos tornaram-se a base para os estudos ambientais, uma vez que possibilitam compreender o funcionamento do objeto em análise e dos processos atuantes de forma integrada, rompendo, portanto, com as análises cartesianas e fragmentadas (BERTALANFFY, 1973). Diante destas considerações, no contexto das bacias hidrográficas, compreender as interrelações entre os componentes biofísicos e o componente antrópico na sua totalidade, é algo essencial.

Assim, a proposta geossistêmica de Bertrand (1971) se apresenta como adequada aos estudos ambientais. O autor define no seu esboço teórico-metodológico a categoria de análise da geografia - paisagem, e a adota para realizar a sua análise. Na sua concepção, a paisagem não deve ser compreendida não como simples adição de elementos dispostos em um arranjo espacial, mas como o resultado de uma combinação dinâmica de elementos biofísicos e antrópicos, que interagem e se encontram em perpétua evolução. Por conseguinte, a aplicação dos geossistemas nos estudos ambientais permite identificar, analisar e avaliar o estado das unidades de paisagem em diferentes escalas, sendo apropriada para os estudos de bacias hidrográficas.

No campo da geomorfologia, o estudo de bacias hidrográficas possui destaque, na medida em que a rede de drenagem constitui fator essencial na esculturação e evolução da paisagem. As interações que ocorrem entre os processos relacionados aos elementos do meio natural e as ações antropogênicas, geralmente geram repercussões sobre este sistema ambiental. Esses impactos promovem ajustes frequentes na dinâmica do sistema ambiental.

A bacia hidrográfica do rio Aningas abrange uma pequena área inserida totalmente no município de Pirambu, Sergipe. Este sistema hidrográfico drena uma paisagem que apresenta certa homogeneidade no que se refere aos aspectos abióticos. Entretanto, no que diz respeito aos tipos de uso das terras constata-se, na atualidade, uma mudança significativa, com possíveis implicações para os recursos hídricos.

Neste sentido, o presente artigo tem por objetivo analisar a bacia do rio Aningas com base no modelo dos geossistemas, com ênfase nas intervenções antrópicas associadas aos tipos de uso. Os estudos poderão contribuir para subsidiar propostas de planejamento e gestão ambiental na área da bacia em análise.

\section{Materiais e métodos}

Este estudo baseia na análise integrada da paisagem e desenvolveu-se apoiado nos princípios sistêmicos da Teoria Geral dos Sistemas (BERTALANFFY, 1973), que reconhece a relação de interdependência entre os componentes de um sistema, a partir das trocas de energia e matéria estabelecidas entre eles. 
Entretanto, tal sistema está sujeito a possíveis alterações que possam ocorrer quando expostos à interferência de algum fator externo.

A difusão dos princípios sistêmicos alcançou os ramos da Geografia Física. Assim, a sua aplicação na análise do meio ambiente se consolidou com propostas teórico-metodológicas como as do modelo geossistêmico (BERTRAND, 1971) e da ecodinâmica (TRICART, 1977). Ambas as propostas inserem as ações antrópicas associadas, principalmente, aos processos econômicos presentes no espaço geográfico, como elementos capazes de interferir e modificar as relações dinâmicas entre os processos naturais. Portanto, o uso e ocupação das terras resultam sempre em novos ajustes no sistema ambiental dominante em uma paisagem.

Esta compreensão é corroborada por RODRIGUEZ, SILVA e CAVALCANTI, 2007, p.155 que afirmam o seguinte,

O homem não modifica as leis da Natureza, mas muda de forma significativa as condições de sua manifestação. [...] A paisagem, por mais que seja transformada, continua como parte da Natureza, subordinando-se às leis naturais. O homem somente utiliza as leis naturais para alcançar seus propósitos, modificando, espontânea ou conscientemente, a direção e a velocidade da evolução paisagística.

O enfoque sistêmico é compatível com estudos em bacias hidrográficas, porque este sistema apresenta uma dinâmica que se relaciona, primeiramente, com os processos do ciclo hidrológico e também com dinâmica social, pois o fator antrópico intervém nos processos hidrodinâmicos de diferentes maneiras construindo barramentos nos canais fluviais, desviando a água dos canais para áreas de culturas irrigáveis, alterando a mata ciliar dos rios e retirando sedimentos das margens e leito, entre outros.

Christofoletti (1980, p. 102) define bacia hidrográfica como "uma área drenada por um determinado rio ou por um sistema fluvial". E, embora existam fatores de diferentes origens que interagem na bacia, o escoamento fluvial consiste no processo fundamental para a esculturação da geometria dos canais de drenagem e das formas de relevo na paisagem.

Para a realização da análise da bacia do rio Aningas foram definidos os seguintes procedimentos: levantamento bibliográfico, análise e seleção de material cartográfico junto à órgãos públicos do estado de Sergipe - Secretaria de Estado do Planejamento, Secretaria de Estado do Meio Ambiente e dos Recursos Hídricos, Empresa Brasileira de Pesquisa Agropecuária - Tabuleiros Costeiros, Companhia de Desenvolvimento Industrial e de Recursos Minerais de Sergipe. 
Para a confecção dos produtos cartográficos da área de estudo foram empregadas ferramentas do SIG (Sistema de Informação Geográfica) a partir do software ArcGIS 9.3, e na elaboração da base cartográfica utilizados os seguintes materiais: mapa topográfico, folha Japaratuba (SC.24-Z-B-V), escala 1:100.000, da Superintendência do Desenvolvimento do Nordeste (SUDENE, 1974); texto e mapas temáticos do Projeto RADAMBRASIL (BRASIL, 1983), escala 1:1.000.000; texto e mapa da Geologia e Recursos Minerais do Estado de Sergipe, escala 1:250.000 (SANTOS et al., 1998); mapa de solo da folha Japaratuba (SC.24-ZB-V), escala 1:100.000, do Projeto de Levantamento de Reconhecimento de Média Intensidade dos Solos da Região dos Tabuleiros Costeiros e da Baixada Litorânea do Estado de Sergipe (LOPES; OLIVEIRA NETO, 1999) e fotografias aéreas, coloridas, escala 1:25.000, da Base Cartográfica dos Municípios Litorâneos de Sergipe (SEPLAN/SE 2003). Além disso, foram realizados trabalhos de campo para observar a organização dos compartimentos morfológicos na paisagem e conhecer a distribuição das atividades produtivas nas terras da bacia hidrográfica em análise.

\section{Resultados e discussão}

O rio Aningas e seus afluentes compõem uma bacia hidrográfica cuja área corresponde a aproximadamente $21 \mathrm{~km}^{2}$, situada totalmente no município de Pirambu, Sergipe (Figura 01). Juntamente com a bacia do rio Sapucaia, ela integra o grupo de pequenas bacias costeiras, GC-1, sendo uma Unidade de Planejamento (UP3) da Secretaria de Estado do Meio Ambiente e dos Recursos Hídricos de Sergipe. 


\section{LOCALIZAÇÃO DA ÁREA DE ESTUDOS}

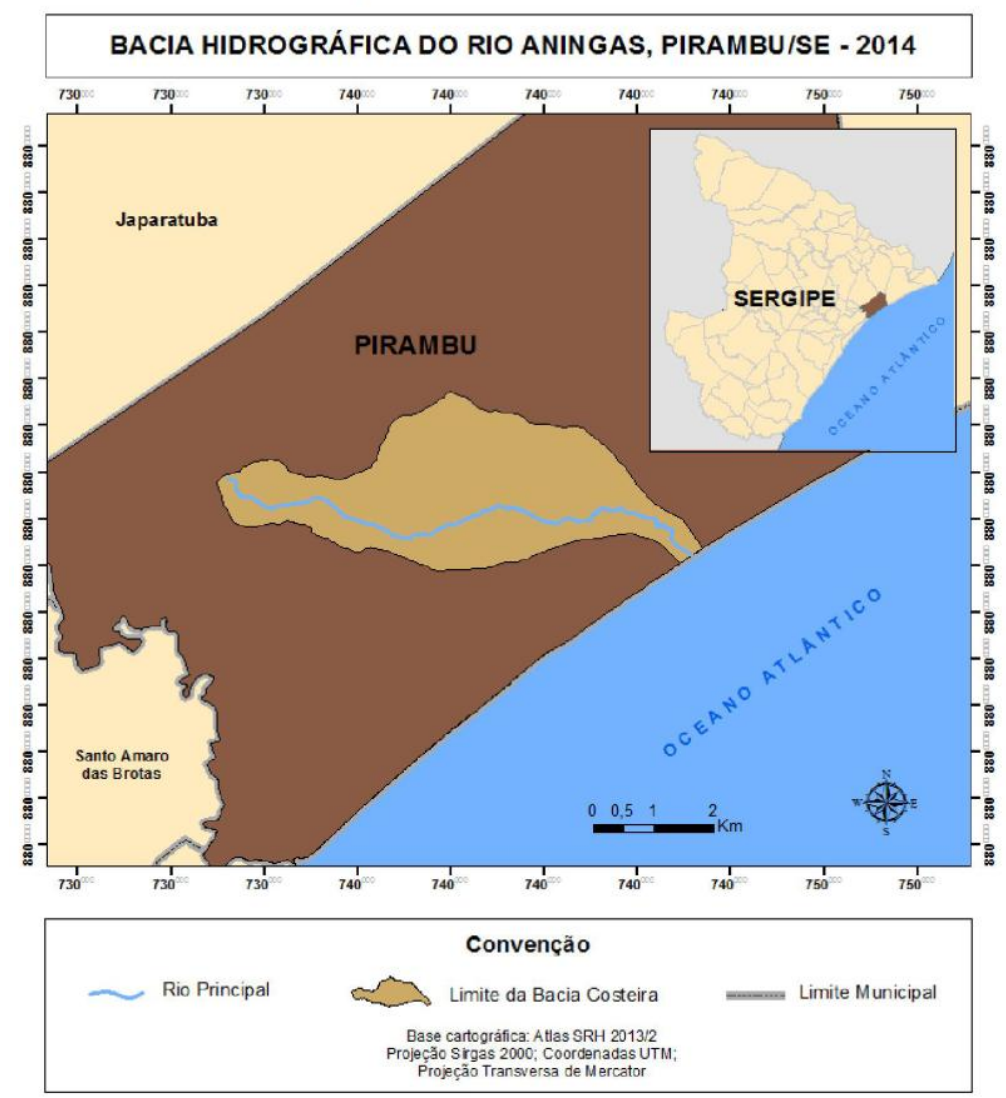

Figura 01 - Mapa de localização da bacia hidrográfica do rio Aningas. Pirambu-SE

Fonte: Menezes (2013)

Nesta análise, o estudo dos condicionantes ambientais se faz necessário. Assim, foram abordados os elementos naturais - clima, geologia, geomorfologia, cobertura vegetal e hidrografia, bem como as ações antrópicas, com ênfase nos tipos de uso das terras dos geossistemas.

O clima constitui importante fator ambiental, tanto por comandar os processos morfogenéticos atuantes na esculturação da paisagem através da intensidade e duração da chuva, como por influenciar diretamente na disponibilidade hídrica de uma área, condição importante para o desenvolvimento das atividades produtivas e para a cobertura vegetal.

Na bacia hidrográfica do rio Aningas o clima é Megatérmico Tropical Subúmido e apresenta duas estações bem definidas, uma caracterizada pela concentração das precipitações, no período outono-inverno, com destaque para o trimestre de maio, junho e julho, e uma estação seca no período primavera-verão. Os totais pluviométricos situam-se em torno de $1200 \mathrm{~mm}$ anuais. As temperaturas não variam 
significativamente durante o ano, situando-se as médias anuais entre $23^{\circ} \mathrm{C}$ e $28^{\circ} \mathrm{C}$ (ALVES, 2010; FONTES, 1984). A pequena amplitude térmica se justifica por se tratar de uma área litorânea e a proximidade com o oceano proporciona condições climáticas mais estáveis. Assim, a distribuição anual da pluviosidade constitui o elemento principal para a caracterização climática.

Com relação à geologia, a área integra a bacia sedimentar Sergipe-Alagoas e está caracterizada por unidades litológicas das Formações Superficiais Continentais Cenozoicas, compreendendo o Grupo Barreiras e depósitos quaternários aluviais, marinhos e eólicos (BRASIL, 1983; SANTOS et al.,1998). O Grupo Barreiras predomina no alto e médio curso, enquanto os depósitos recentes se encontram no baixo curso, na abrangência do setor litorâneo.

Na costa brasileira, o Grupo Barreiras apresenta-se constituído por sedimentos terrígenos - cascalhos, conglomerados, areias finas e grossas e níveis de argila - pouco ou não consolidados, com cores que variam do amarelo-ocre ao vermelho-acastanhado, na dependência do teor de ferro. A ocorrência de um nível conglomerático de cimentação ferruginosa favorece a conservação das morfologias de topos tabulares (BRASIL, 1983; FONTES, 1984; SANTOS et al., 1998).

Geomorfologicamente, a paisagem da bacia do rio Aningas apresenta feições morfológicas que refletem a natureza dos litotipos em interação com o clima. Duas unidades caracterizam-na: os Tabuleiros Costeiros e a Planície Costeira.

Os Tabuleiros Costeiros estão compostos pelos seguintes elementos: topos, bordos, vertentes e rampas coluvio-aluviais. Os topos são caracterizados por topografia sub-horizontal com gradientes de declividade que variam entre $0^{\circ}$ e $5^{\circ}$, podendo apresentar pequenas depressões, que acumulam água durante o período chuvoso, podendo formar pequenas lagoas temporárias (ALVES; SILVA; FONTES, 2013). Com frequência, estes topos são capeados por espraiamentos arenosos, que favorecem a infiltração das águas pluviais e reduz o desenvolvimento de processos erosivos lineares.

Os bordos dos tabuleiros, geralmente são entalhados por cabeceiras dos canais de drenagem. Dependendo do gradiente de declividade, os processos associados aos movimentos de massa rápidos ou lentos podem ser desencadeados. Os bordos e as vertentes mais íngremes se mostram como os ambientes mais suscetíveis aos deslizamentos (ALVES, 2010).

Segundo a autora referida "no sopé dos tabuleiros, encontram-se depósitos de sedimentos, sobretudo arenosos, de granulometria heterogênea e dimensões variáveis com aspecto de cones ou leques, que suavizam o declive" (ALVES, 2010, p. 105). Estas características identificam as rampas coluvio-aluviais, originadas a partir da atuação de processos pluviais e fluviais que remobilizaram os materiais ao longo das 
vertentes dos Tabuleiros Costeiros. Essas feições possuem altimetria média que não ultrapassa 30 metros. As vertentes apresentam uma tendência à convexidade e seu contato com planície de inundação se faz de forma gradual e suave. A dissecação está condicionada pelo escoamento fluvial, gradiente de declividade e estado da cobertura vegetal.

A unidade geomorfológica Planície Costeira está composta por: dunas costeiras inativas e ativas, terraços marinhos holocênicos, lençóis de areia e dunas embrionárias (ALVES, 2010). Estas feições são formadas por depósitos de sedimentos holocênicos e foram elaboradas por processos resultantes da dinâmica marinha, fluvial e eólica.

A vegetação na bacia do rio Aningas está condicionada por fatores climáticos e edáficos. Na área, ela está representada pela Floresta Estacional Semidecidual, Cerrado, Restinga e Campos de Várzea. A primeira formação vegetal citada corresponde à cobertura original dos Tabuleiros Costeiros, e, na atualidade, apresenta diferentes graus de antropização devido à implantação de culturas cíclicas e pastagem. Poucos fragmentos em bom estado de conservação se distribuem sobre a classe dos solos ARGISSOLOS VERMELHO-AMARELOS (LOPES; OLIVEIRA NETO, 1999). Sobre os topos com espraiamentos arenosos a composição florística conjuga espécies do Cerrado e da Restinga, enquanto apenas esta última formação coloniza as feições morfológicas da Planície Costeira. Nos fundos de vale são encontradas as espécies higrófitas e higrófilas características dos Campos de Várzea.

Na paisagem da bacia, dominam interflúvios tabulares com características diversas e a rede de drenagem apresenta um padrão misto - subdentrítico e subparalelo. O rio Aningas apresenta perfil longitudinal de baixo gradiente, permitindo inferir, a existência de pequena declividade entre a nascente e o exutório (FONTES, 1984). Os vales em manjedoura ou de fundo chato, comumente são preenchidos por material aluvial de granulometria predominantemente fina. No período seco, o canal de drenagem principal apresenta intermitência no alto curso. Entretanto, apesar do baixo potencial hídrico o rio Aningas é importante para atividades desenvolvidas pela população.

O condicionante antrópico, na área de estudo constitui importante agente modificador da paisagem e responsável pela intensificação dos processos morfogenéticos, em razão da retirada da cobertura vegetal para implantação das atividades agropecuárias e extrativas.

A agricultura engloba os cultivares de subsistência (mandioca, feijão, milho) e a cocoicultura se destaca como a principal produção comercial, devido à adaptabilidade do coco-da-baía (Cocus nucifera) às condições climáticas e edáficas. Na limpeza do terreno se utiliza com frequência a prática da queimada, que deixa setores do solo exposto, favorecendo a atuação dos processos de erosão linear e o surgimento formas erosivas - sulcos, ravinas e voçorocas (Figuras 2 e 3). 


$\begin{gathered}\text { XVII Simpósio Brasileiro } \\ \text { de Geografia Fisica Aplicada }\end{gathered}$
$\begin{aligned} & \text { I Congresso Nacional } \\ & \text { de Geografia Física }\end{aligned}$

Nos dias atuais, a possibilidade de pavimentação da estrada SE-100, vetor de integração do litoral sul, centro e norte do estado de Sergipe, está contribuindo para estimular a especulação imobiliária na área. Os loteamentos de segunda residência começam a surgir, sendo visível a remoção parcial ou até mesmo total da vegetação em áreas dos interflúvios da bacia hidrográfica, acarretando consequentemente na aceleração do processo de degradação paisagística e alteração da dinâmica dos processos morfogenéticos. Recentemente, mais uma nova atividade está sendo implantada no alto do rio Aningas - a aquicultura. A construção de viveiros para criação de camarão ou peixes começa a se destacar na área da planície de inundação dos vales fluviais.

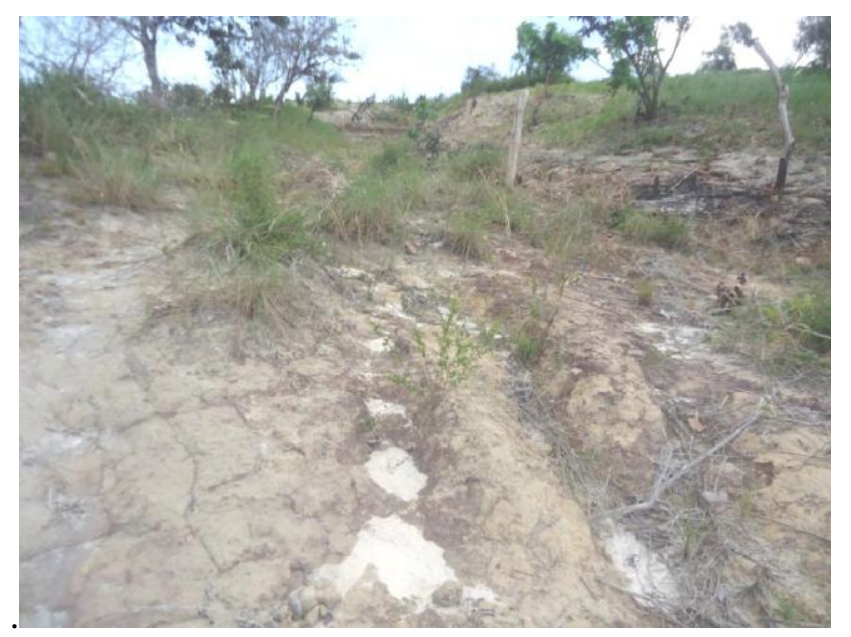

Figura 02 - Vertente com evidências de retirada da vegetação, uso de queimada e formas erosivas resultante do escoamento superficial concentrado - Alto/Médio curso do rio Aningas, Pirambu/SE

Fonte: Menezes (2013)

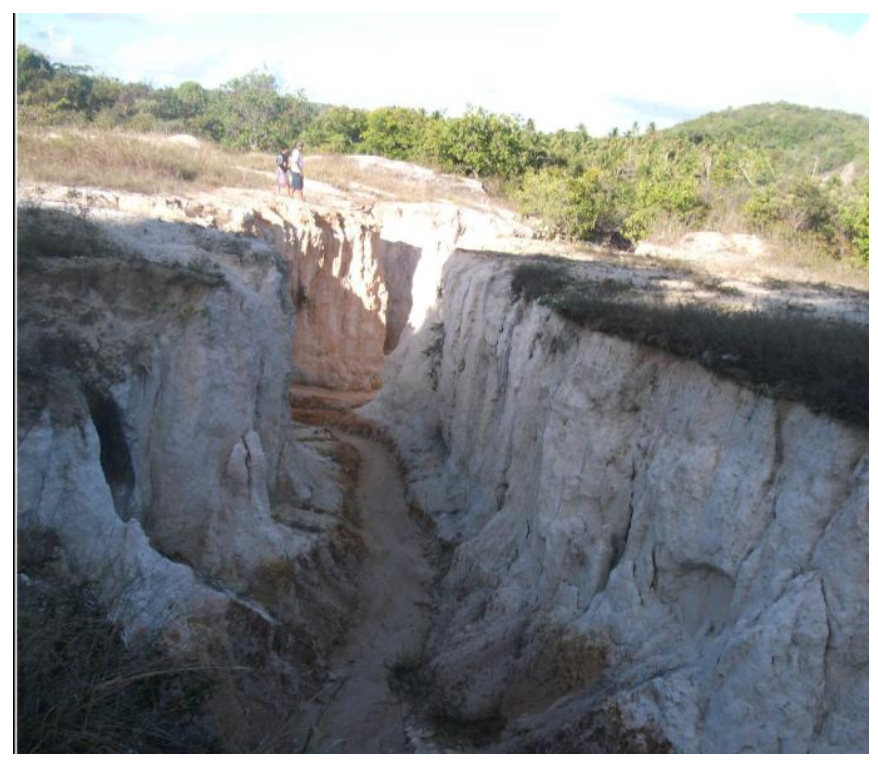

Figura 03 - Voçoroca nos sedimentos do Grupo Barreiras resultante de exploração mineral - corte de estrada Médio curso do rio Aningas, Pirambu/SE 
Fonte: Menezes (2013)

\subsection{Análise geossistêmica da bacia do rio Aningas}

A aplicação da proposta metodológica geossistêmica de Bertrand (1972), na bacia do rio Aningas, permitiu identificar dois geossistemas: Geossistema dos Tabuleiros Costeiros e o Geossistema da Planície Costeira. A individualização dessas unidades teve por base os aspectos morfológicos, litoestratigráficos e a morfodinâmica.

Para conduzir a análise em nível taxonômico compatível com a área de estudo, os Geossistemas foram subdivididos em Geofácies, pois estas unidades apresentam maior homogeneidade na paisagem. Seguindo este princípio foi elaborado o mapa Geossistêmico para a bacia onde estão representados dois Geossistemas e sete Geofácies (Figura 04).

O Geossistema Tabuleiros Costeiros está integrado por quatro unidades - Geofácies em Biostasia Precária dos Topos Arenosos, Geofácies em Biostasia Precária das Vertentes Vegetadas, Geofácies em Resistasia das Vertentes Antropizadas e Geofácies em Resistasia das Planícies Aluviais (Figura 04).

Este Geossistema apresenta certa complexidade por justapor Geofácies individualizadas por características litoloestratigráficas, topográficas, pelo estado da vegetação e tipos de uso das terras. Além disso, reúne formas herdadas de sistema morfoclimático pretérito, como os topos tabuliformes, que apresentam morfogênese lenta e relativa estabilização, devido a ocorrência do nível concrecionário no Grupo Barreiras e aspectos da topografia e, formas que se encontram em plena evolução no contexto climático atual, a exemplo dos anfiteatros das cabeceiras de drenagem instalados nos bordos e das formas erosivas atuais - sulcos, ravinas e voçorocas. 


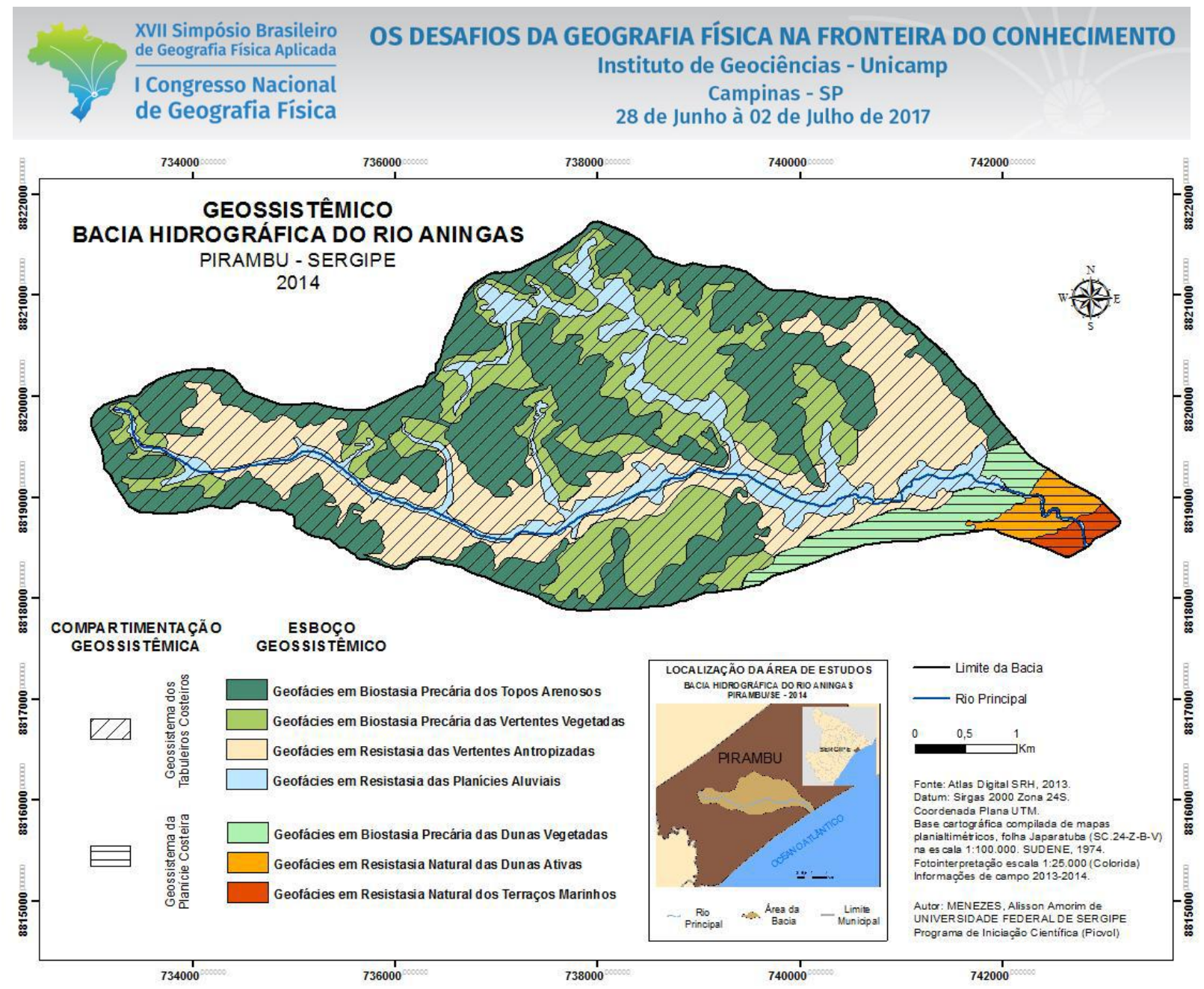

Figura 04 - Mapa geossistêmico da bacia hidrográfica do rio Aningas, Pirambu-SE.

Fonte: Menezes (2013)

O Geossistema Planície Costeira está composto três unidades - Geofácies em Biostasia Precária das Dunas Vegetadas, Geofácies em Resistasia Natural das Dunas Ativas e Geofácies em Resistasia Natural dos Terraços Marinhos (Figura 04).

Este Geossistema está situado no setor a leste da bacia hidrográfica do rio Aningas, caracterizado morfologias elaboradas a partir das interações dos fatores climáticos, litológicos e atuação dos processos morfodinâmicos oceanográficos, fluviais e eólicos. A construção de feições se relaciona diretamente com fenômenos decorrentes da variação do nível do mar, no período Quaternário (ALVES, 2010).

Para a identificação do estado dos Geofácies, de ambos os Geossistemas, com base na biostasia ou resistasia foram observadas as características dos ambientes na paisagem. Desse modo, os ambientes biostásicos são aqueles onde se verificam os processos favoráveis à pedogênese, a ação dos processos morfogenéticos é nula ou atenuada pelas características topográficas e observa-se menor intervenção antrópica. Por outro lado, nos ambientes resistásicos predominam a morfogênese e os processos erosivos 
se manifestam amplamente na paisagem em função das interações dos processos naturais com as ações antropogênicas, representadas pelos usos das terras.

Os Geofácies que compõe os Geossistemas da bacia do rio Aningas se encontram em diferentes estádios de evolução na paisagem. Tal condição reflete, principalmente, o grau das intervenções antrópicas representadas pelos tipos de uso dos recursos naturais, que propicia o desenvolvimento ou a intensificação dos processos morfogenéticos.

\section{Considerações finais}

O desenvolvimento deste estudo com base no modelo dos geossistemas possibilitou alcançar o objetivo definido e compreender a dinâmica do sistema ambiental dominante na bacia hidrográfica do rio Aningas. Assim, pode-se afirmar que os fundamentos teóricos e os procedimentos metodológicos foram adequados à investigação.

A análise permitiu identificar e caracterizar condicionantes biofísicos do sistema onde se inserem os Geossistemas Tabuleiros Costeiros e Planície Costeira que compõem a paisagem da bacia referida, revelando ainda que os principais problemas ambientais que se manifestam e a descaracterização da paisagem estão relacionados com as intervenções antrópicas, associadas aos tipos de uso das terras.

Requerem atenção especial:

- Geofácies em Resistasia das Vertentes Antropizadas, por inserirem setores com elevada declividade, onde se situam os anfiteatros das cabeceiras de drenagem, e as rampas coluviais com textura argiloarenosa, aspectos favoráveis à ocorrência dos movimentos de massa - os tipos de uso podem acentuar a condição morfodinâmica dessa unidade de paisagem;

- Geofácies em Resistasia das Planícies Aluviais por abranger uma área de recepção de sedimentos. Assim, com a retirada da vegetação original para implantação de atividades agropecuárias a disponibilidade de sedimentos para os canais se eleva, em particular, durante o período chuvoso quando ocorre a intensificação do escoamento superficial - o assoreamento pode ser constatado em certos setores do canal do rio principal;

- Todas as Geofácies do Geossistema Planície Costeira por estarem compostas por sedimentos arenosos inconsolidado e sujeitas a processos morfodinâmicos oceanográficos, eólicos e fluviais atuantes na dinâmica natural do ambiente litorâneo. 


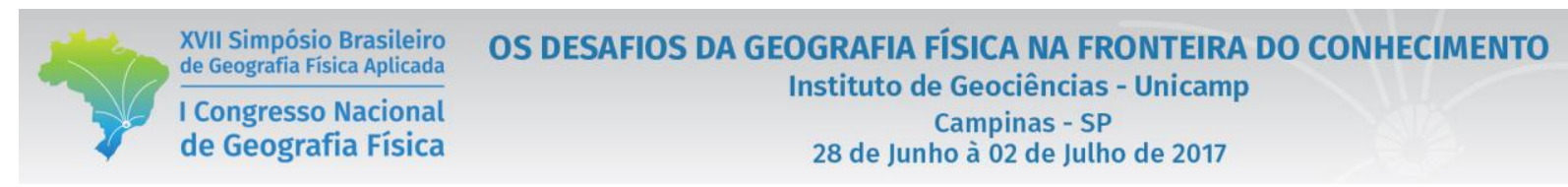

Os estudos permitiram maior conhecimento da área, e podem contribuir para subsidiar o planejamento ambiental e dos recursos hídricos, além de prevenir o desencadeamento dos impactos ambientais no município de Pirambu.

\section{Bibliografia}

ALVES, N. M. S. Análise geoambiental e socioeconômica dos municípios costeiros do litoral norte do estado de Sergipe - diagnóstico como subsidio ao ordenamento e gestão do território. 2010, 382f.:il. Tese de doutorado (Doutorado em Geografia) - NPGEO, Universidade Federal de Sergipe, São Cristóvão, 2010.

ALVES, N. M. S.; SILVA, D. B.; FONTES, A. L. Análise da paisagem e avaliação morfodinâmica do município de Pirambu - Sergipe, Brasil. IN: XIV ENCUENTRO DE GEOGRAFOS DE AMERICA LATINA, 2013, Anais...: Lima: $14^{\circ}$ EGAL, 2013. 1 CD-ROM.

BERTALANFFY, L. Teoria geral dos sistemas. Petrópolis, Vozes, 1973.

BERTRAND, G. Paisagem e geografia física global: esboço metodológico. Caderno de Ciências da Terra, São Paulo, n. 13, p. 1-27, 1972.

BRASIL. Ministério das Minas e Energia. Projeto RADAMBRASIL: folha SC.24/25 Aracaju/Recife: geologia, geomorfologia, pedologia, vegetação, uso potencial da terra. Rio de Janeiro, 1983. 851 p. (Levantamento de Recursos Naturais,30).

CHRISTOFOLETTI, A. Geomorfologia. S. Paulo: Editora Edgard Blucher Ltda, 1980.

FONTES, A. L. Geomorfologia da área de Pirambu e adjacências (Sergipe). 1984. 152 f. Dissertação (Mestrado) - Instituto de Geociências, Universidade Federal da Bahia, Salvador, 1984.

LOPES, O. F.; OLIVEIRA NETO, M. B. de. Levantamento de reconhecimento da média intensidade dos solos da região dos tabuleiros costeiros e da baixada litorânea do Estado de Sergipe. Japaratuba: SC.24-Z-B-V. Aracaju: EMBRAPA Tabuleiros Costeiros, 1999. 1mapa color. Escala 1:100.000.

MENEZES, A. A. Compartimentação geossistêmica da paisagem da bacia hidrográfica do rio Aningas Pirambu, Sergipe. São Cristóvão: UFS, Pró-Reitoria de Pós-Graduação e Pesquisa, 2014. 36 f. Relatório final do Programa Institucional de Bolsas de Iniciação Científica.

RODRIGUEZ, J. M. M; SILVA. E. V.; CAVALCANTI. A.P. B. Geoecologia da paisagem: uma visão geossistêmica da análise ambiental. Fortaleza: EDUFC, 2007.

SANTOS, R. A. et al.. Geologia e recursos minerais do estado de Sergipe: texto explicativo do mapa geológico do estado de Sergipe. Brasília: CPRM; Aracaju: CODISE, 1998.

SERGIPE. Secretaria do Planejamento e da Ciência e Tecnologia. Atlas digital sobre recursos hídricos de Sergipe. Aracaju, 2002. 1 CD-ROM.

Base cartográfica dos municípios litorâneos de Sergipe. Aracaju, 2003. Fotografias aéreas. Escala 1:25.000. 1 CD-ROM. Cobertura do município de Pirambu.

TRICART, J. Ecodinâmica. Rio de Janeiro: IBGE, 1977. 91 p. (Recursos naturais e meio ambiente, 1). 